\title{
In situ Monitoring By Raman Spectroscopy of Lysozyme Conformation during "Nanotemplate" Induced Crystallization
}

\author{
Claudio Nicolini ${ }^{1,2,3 *}$, Luca Belmonte ${ }^{1}$, George Maksimov ${ }^{3}$, Nadezda Brazhe ${ }^{3}$ and Eugenia Pechkova ${ }^{1}$
}

${ }^{1}$ Biophysics and Nanobiotechnology Laboratories University of Genoa, Genoa and Nano world Institute Fondazione El.B.A. Nicolini, Bergamo, Italy ${ }^{2}$ European Synchrotron Radiation Facility, Grenoble, France

${ }^{3}$ Biophysics Department, Biological Faculty, Moscow State University, Russian Federation, Russia

\begin{abstract}
Using Raman spectroscopy and lysozyme, this latter as model protein, we investigate the differences in protein conformation before and after LB nanotemplate-induced crystal nucleation and growth. It was found that the main difference in lysozyme conformation is associated to the higher amount of S-S bonds in lysozyme of LB crystals, probably in C-end of protein, resulting in the higher stiffness of the lysozyme molecules and LB crystal in a whole. Growth in size of LB crystal over time is also accompanied by the formation of S-S bonds. Atomic structure, determined by X-ray diffraction, correlates Raman spectroscopy results confirm the main differences between LB and classical crystals are in terms of water molecules environment previously associated to the increased radiation stability of LB crystals.
\end{abstract}

Keywords: Raman Spectroscopy; Thin LB Films; Lysozyme; Crystal Growth

\section{Introduction}

Raman spectroscopy is attractive as a potential diagnostic tool because it requires no extrinsic labeling, is not limited by masking water contributions, and is inherently a multiplexing technique. Raman-based measurements of biological samples have already been exploited for the identification of molecular specific markers for disease detection and monitoring [1]. The use of fiber optic technology coupled with Raman spectroscopy is ideal for application to aqueous solutions, either with or without Langmuir-Blodgett (LB) nanotemplate [2,3]. Raman is expected to evaluate the lysozyme concentration changes in vapour diffusion hanging drop method with and without LangmuirBlodgett nanotemplate. Raman spectra have previously been subjected to quantitative infrared partial least-squares (PLS) models with remarkable success [4]. The PLS model generated correlates the spectral region from 2700 to $3600 \mathrm{~cm}^{-1}$ with the concentration (g/ $\mathrm{ml}$ ) of lysozyme. This spectral region encompasses vibrations due to the protein $\mathrm{C}-\mathrm{H}$ stretches centered at $2950 \mathrm{~cm}^{-1}$ and the water $\mathrm{O}-\mathrm{H}$ stretches centered at $3230 \mathrm{~cm}^{-1}[5,6]$.

We intend to reproduce their data using the modified hanging drop method with the LB nanotemplate of the protein, deposited on the glass cover slide brought in the contact with the protein solution drop. Hanging drop vapor diffusion crystallization technique, when used with Langmuir-Blodgett thin films results in both acceleration of the protein nucleation and crystal growth; moreover, the use of the nanotemplate seems to improve both crystal quality and the resistance to the radiation damage [7-9]. In several protein systems the nucleation was observed using the template, while classical hanging drop was not successful. Using the lysozyme as the model systems, we expect to understand from the Raman spectra the differences between the mechanism of the crystallization with and without the nanotemplate, and estimate the influence of the LB nanotemplate to the protein nucleation and growth. In this paper for the first time we present results of RS study of the mechanism of the crystallization with and without the nanotemplate, and estimate the influence of the LB nanotemplate to the protein nucleation and growth. Langmuir-Blodgett (LB) thin films used as template for protein crystallization develop crystal with improved radiation stability in presence of third generation synchrotron facility due to their different arrangements [10-22]. One of the main reasons of this success is apparently due to water molecules distribution around protein backbone [18].

\section{Materials and Methods}

\section{Crystallization of lysozyme}

The protein solution used for both the $\mathrm{LB}$ and the classical hangingdrop method were of $18 \mathrm{mg} / \mathrm{ml}$ in $50 \mathrm{mM} \mathrm{Na}_{2} \mathrm{HPO}_{4} \mathrm{pH} 10.41 \mathrm{mM}$ EDTA with a reservoir of $400 \mathrm{mM} \mathrm{Na}_{2} \mathrm{HPO}_{4}$ at $\mathrm{pH} 10.410 \mathrm{mM}$ EDTA at RT. Moreover, the LB vapour diffusion hanging drop modified method was utilized as described in Pechkova and Nicolini [15]. Lysozyme thin film was prepared on the water-area interface and compressed to a surface pressure of $25 \mathrm{mN} / \mathrm{m}$ by means of a Langmuir-Blodgett trough [16].

\section{LB thin film preparation}

Lysozyme thin films are prepared on the water-area interface and compressed to a surface pressure, dependent on the proteins that have to be crystallized. The protein solution after filtration with Millex HV (Syringe-Driven Filter Unit, Millipore) is spread over the water surface with Hamilton syringe without use of any dispersant. The protein monolayer is compressed immediately after spreading to the surface pressure of $20 \mathrm{mN} / \mathrm{m}$ by two through teflon barriers with compression speed of $70 \mathrm{~cm} / \mathrm{min}$. The transfer of protein monolayer from the

*Corresponding author: Claudio Nicolini, Nanoworld Institute Fondazione ELBA Nicolini, Bergamo and Eminent Chair of Biophysics via Pastore 3 University of Genova, Genova, Italy, Tel: +39 010 35338217; Fax: +39 010 35338215; E-mail: claudio.nicolini@unige.it

Received November 01, 2013; Accepted November 30, 2013; Published December 04, 2013

Citation: Nicolini C, Belmonte L, Maksimov G, Brazhe N, Pechkova E (2013) In situ Monitoring By Raman Spectroscopy of Lysozyme Conformation during "Nanotemplate" Induced Crystallization. J Microb Biochem Technol 6: 009-016. doi:10.4172/1948-5948.1000114

Copyright: ( 2013 Nicolini C, et al. This is an open-access article distributed under the terms of the Creative Commons Attribution License, which permits unrestricted use, distribution, and reproduction in any medium, provided the original author and source are credited 
Citation: Nicolini C, Belmonte L, Maksimov G, Brazhe N, Pechkova E (2013) In situ Monitoring By Raman Spectroscopy of Lysozyme Conformation during "Nanotemplate" Induced Crystallization. J Microb Biochem Technol 6: 009-016. doi:10.4172/1948-5948.1000114

subphase (water) surface onto solid support is then performed by touching the support in parallel to the subphase surface in accordance with the LB technique (horizontal lift). Siliconized circular glass cover slides (Hampton Research) washed in distilled water and dried in a gaseous nitrogen flux are used as substrate for two subsequent protein film depositions. A protein monolayer is then deposited on the siliconized glass cover slide of $20 \mathrm{~mm}$ diameter (Hampton Research) by the Langmuir-Schaeffer method. This highly ordered protein nanotemplate is utilized in hanging-drop protein crystallization. The drop of protein solution and the precipitant (salt) is placed on the glass slide covered by LB thin film nanotemplate. As in the classical hangingdrop method, the glass slide with the protein template and the drop of protein solution was sealed on the crystallization plate (Limbro plate, Hampton Research) using vacuum grease.

\section{Raman spectroscopy}

Raman spectroscopy was used to evaluate the lysozyme concentration and the amount of water within the crystallization drop, simultaneously. Raman spectroscopy probes the vibrational energy levels of the bonds within the protein and the water; as previously shown [17-22] unique water environment in LB crystals really differ from classical one. A 6 microliter protein drop is deposited on a microscope cover glass. The cover glass was then inverted and placed over a $3 \mathrm{ml}$ vessel containing $0.8 \mathrm{ml}$ of a NaCl/buffer reservoir ranging in ionic strength from 0.34 to $2.73 \mathrm{M}$. The top of each vessel is greased to ensure an airtight seal. The reaction vessel consists of a $3 \mathrm{~cm}^{3}$ vial. The incident, laser light travels through the cover glass directly into the hanging drop of protein. Since the cover glass does not scatter well at $632.8 \mathrm{~nm}$, the cover glass is optically transparent to the measurement permitting the measurement of lysozyme concentration without contact with the solution and provides spectral coverage from 400 to $3650 \mathrm{~cm}^{-1}$.

In the RAMAN experiments carried out at IBS-Cryogen Lab (Figure 1) we utilized an adapation of our in situ chamber previously utilized with microGISAXS at ID13 [13], namely:
1. Initially, at time equal zero, the $1 \mathrm{ml}$ reservoir concentration is $0.45 \mathrm{NaCl}$ as the one in the drop of 6 microliter on the glass slide containing equal amount ( 3 microliter) of: buffer $0.9 \mathrm{NaCl}$ $0.05 \mathrm{M}$ sodium acetate $\mathrm{pH} 4.5$, protein concentration equal to $40 \mathrm{mg} / \mathrm{ml}$ in order to establish the baseline until the complete proper alignment of the optics and of the laser is achieved;

2. Then we quickly change the salt concentration of the $\mathrm{NaCl} /$ buffer solution in the reservoir which contains a volume of 0.8 $\mathrm{ml}$, namely: for the first 20 minutes with "induced nucleation" solution of $6 \mathrm{ml} \mathrm{NaCl} 3 \mathrm{M}+4 \mathrm{ml} \mathrm{NaAc}$ means $1.8 \mathrm{M} \mathrm{NaCl}$; and for remaining 6 hours with "controlled growth" solution of $3 \mathrm{ml} \mathrm{NaCl} 3 \mathrm{M}+7 \mathrm{ml} \mathrm{NaAc}$ means $0.9 \mathrm{M} \mathrm{NaCl}$. During the entire time interval the RAMAN spectra has been continuously acquired.

3. Next, we repeat the same experiment using the cover slide covered with the 2 monolayer of the Lysozyme LB nanotemplate

As showed in Advances in spectroscopic methods for biological crystals [23] the used apparatus consists of the laser source, the spectrometer and the probe and it was manufactured by Renishaw (Gloucestershire, United Kingdom). Fluorescence and photochemical modification of biological samples by laser beam minimized from 650 to $800 \mathrm{~nm}$ were studied using a NIR $785 \mathrm{~nm}$ laser source. This laser source consists of an air-cooled diode laser RL785, operating at a wavelength of $785 \mathrm{~nm}( \pm 0.25 \mathrm{~nm})$ and supplying a power of $300 \mathrm{~mW}$. Only $50 \mathrm{~mW}$ reach the sample, indeed Raman scattering in biological samples is low. The spectrograph is a Renishaw In Via single-stage spectrometer with a focal length of $250 \mathrm{~mm}$. The Raman signal enters the spectrometer through manually adjustable slits and is dispersed by an NIR-blazed holographic grating of 1200 grooves $\mathrm{mm}^{-1}$. A Renishaw RemCam deepdepletion CCD detector low-noise thermoelectrically cooled at $203 \mathrm{~K}$ is used. It allows a rapid acquisition of Raman spectra over a wide spectral range. Continuous Raman spectra running from 200 to $4000 \mathrm{~cm}^{-1} \mathrm{can}$ be collected with a resolution of $1 \mathrm{~cm}^{-1}$ (SynchroScan method), spikes

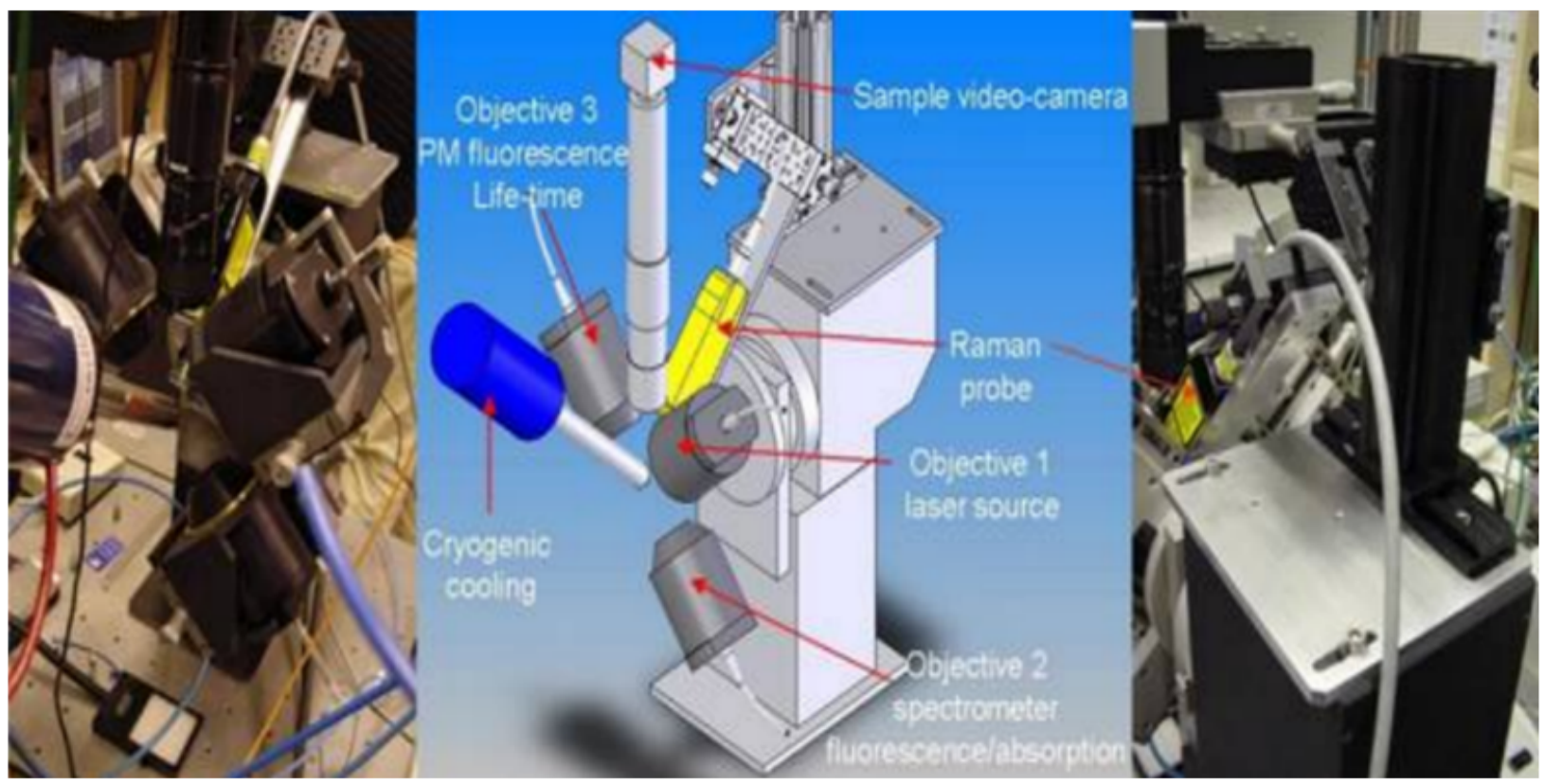

Figure 1: Raman microspectrophotometer at the ESRF cryobench. Image credits ID23 ESRF beam line. 
can be avoided by the 'step and stitch' method. The optics section (for excitation and collection) consists of a compact Raman probe $\left(140\right.$ X 45 X $\left.20 \mathrm{~mm}^{3}\right)$ compatible with X-ray goniometer configured in coaxial back-scattering geometry. This configuration minimizes the required space around the sample and preventing misalignment between the excitation and detection volumes. Acquisition time was of 5 minutes per crystal. Wire 2.0 software was used to control the Raman spectrometer. Further details can be found in Carpentier et al. [23].

\section{Data processing of raman spectra}

In this manuscript were used two softwares for Raman spectra analysis. Mainly SpADS:Spectra Analyzer and Data Sets classificator $[24,25]$ was used for preprocessing while Raman Cooker [26] was used for base line correction. After a preprocessing with SpADS, baseline correction was performed using Raman Cooker and three examples of baseline correction are shown in Figures 2 and 3. For all spectra we performed baseline subtraction to ensure that the Raman peak intensities were calculated correctly without artificial influence of the baseline drift.

\section{X-ray Crystallography}

All X-ray data were collected at ID 14-4, ESRF, Grenoble, France. A beam with Energy of $13.3 \mathrm{keV}$ and a wavelength of $0.932216 \AA$ was used for diffraction pattern collection. All datasets were collected using freshly frozen crystals cryo cooled at $100 \mathrm{~K}$ using their mother liquor containing in addition $30 \%$ of glycerol as cryoprotectant. Classical and LB-film based crystals of approximately the same dimensions and shape were used to collect two complete data sets. Each dataset is composed of 180 images acquired at $1^{\circ}$ and with $1 \mathrm{sec}$ of exposure time. The datasets were recorded using an ADSC Q315r CCD detector. Both data sets were indexed and integrated with MOSFLM [27] and both crystals were processed in space group P43212. Datasets were then scaled with the program SCALA from the CCP4 software package [28]. MATTHEW COEFF [29] of the ccp4 package was used for the calculation of the number of molecules in the asymmetric unit assuming a protein molecular weight of $5.733 \mathrm{kDa}$. The crystal structure was solved by molecular replacement using MOLREP [30]. Structure used as template was PDB ID 2AUB [22]. The protein model obtained from molecular replacement stage was then refined against the classical and LB crystals using REFMAC5 [31,32]. Data were then inspected at the same contour level with COOT [33]. Visual inspection of the two structures were performed using PyMol [34] A cutoff of the resolution was applied to $2.0 \AA$ in order to make the two structure comparable (Figure 4).

\section{Results and Discussion}

Special features of lysozyme, were used for the interpretation of crystal Raman Spectroscopy (Figures 5-7) are shown in Table 2. Raman Spectroscopy peak assignment is based on [35], namely lysozyme molecule has 6 Trp residues. Trp123 is located closely to C-end of the lysozyme. Four S-S bonds with disulfide bonds S6/S127 and S30/S115 located closely to C-end of lysozyme. S-S and S-H bonds' vibration in lysozyme molecules gives Raman Spectroscopy scattering at 505 and $634 \mathrm{~cm}^{-1}$, respectively. There is a Phe residue located nearby disulfide bonds S6/S127 and S30/S115, whereby Raman peak at $865 \mathrm{~cm}-1(\mathrm{~N} 1 \mathrm{H}$ bond vibration in Trp) is the most stable peak and could be used as a reference to compare the relative presence of other peaks in the region $400-1000 \mathrm{~cm}^{-1}$. C-terminal end of lysozyme molecule is more flexible and susceptible to changes in the environment, with respect to N-terminal.

We demonstrated, as showed in Figure 5, that Raman Spectra of LB lysozyme, of the same size $(30 \mu)$ and at different point of time after nucleation ( 2 and $10 \mathrm{~min}$ ) are different due to their different bond vibrations. Observed changes in Raman Spectra correspond to
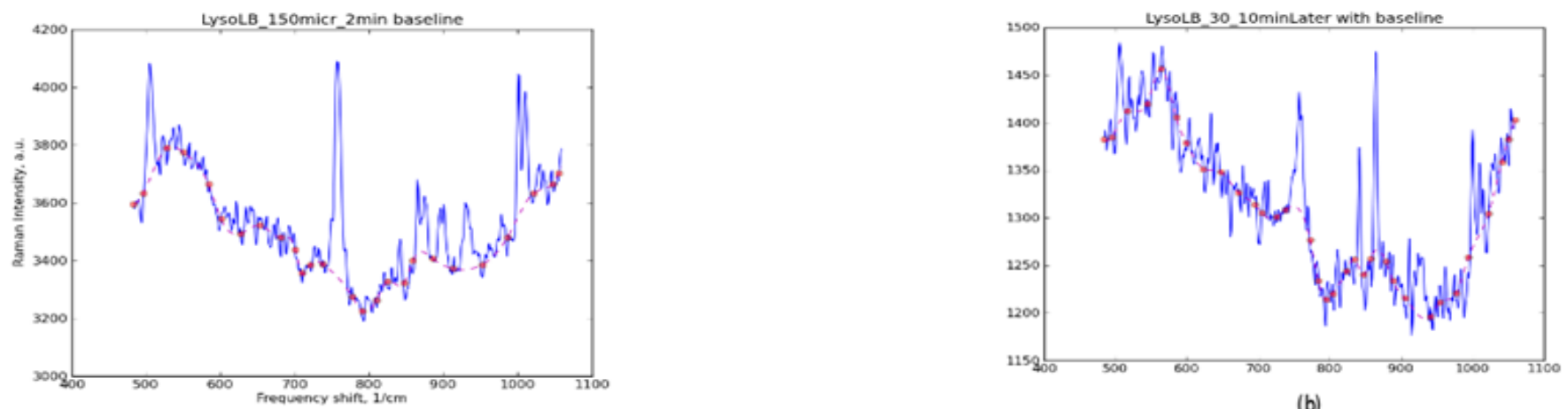

(a)

(b)

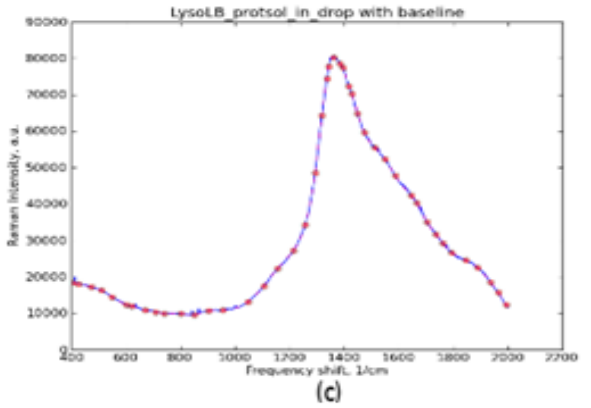

Figure 2: Examples of baseline correction. 
Citation: Nicolini C, Belmonte L, Maksimov G, Brazhe N, Pechkova E (2013) In situ Monitoring By Raman Spectroscopy of Lysozyme Conformation during "Nanotemplate" Induced Crystallization. J Microb Biochem Technol 6: 009-016. doi:10.4172/1948-5948.1000114

\begin{tabular}{|c|c|c|}
\hline \multirow{2}{*}{ Parameters } & Classical & LB \\
\hline & $418 S$ & 4IAT \\
\hline Resolution Range $(\AA)$ & $2.00-40.17(2.00-2.11)$ & $2.00-39.39(2.00-2.11)$ \\
\hline$a=b, c(\AA)$ & 80.3437 .16 & 78.7836 .99 \\
\hline$\alpha=\beta=\gamma\left({ }^{\circ}\right)$ & 90 & 90 \\
\hline Completeness (\%) & 100.0 & 100.0 \\
\hline Mosaicity & 0.97 & 0.54 \\
\hline Spacegroup & \multicolumn{2}{|c|}{ P 43212} \\
\hline I/Sigma & $12.1(8.6)$ & $31.8(20.0)$ \\
\hline $\mathrm{R}_{\text {sym }}$ & 0.199 & 0.066 \\
\hline $\mathrm{R}_{\text {factor }}$ & 0.195 & 0.175 \\
\hline$R_{\text {free }}$ & 0.259 & 0.241 \\
\hline Total number of reflections & 8200 & 7903 \\
\hline R.m.s. on bond length $(A)$ & 0.022 & 0.022 \\
\hline R.m.s. on angles $\left({ }^{\circ}\right)$ & 1677 & 1797 \\
\hline
\end{tabular}

Table 1: Statistics of the X-ray diffraction studies of the two lysozyme crystals, the former growth with classical hanging drop method and the latter growth with LB modified vapour.

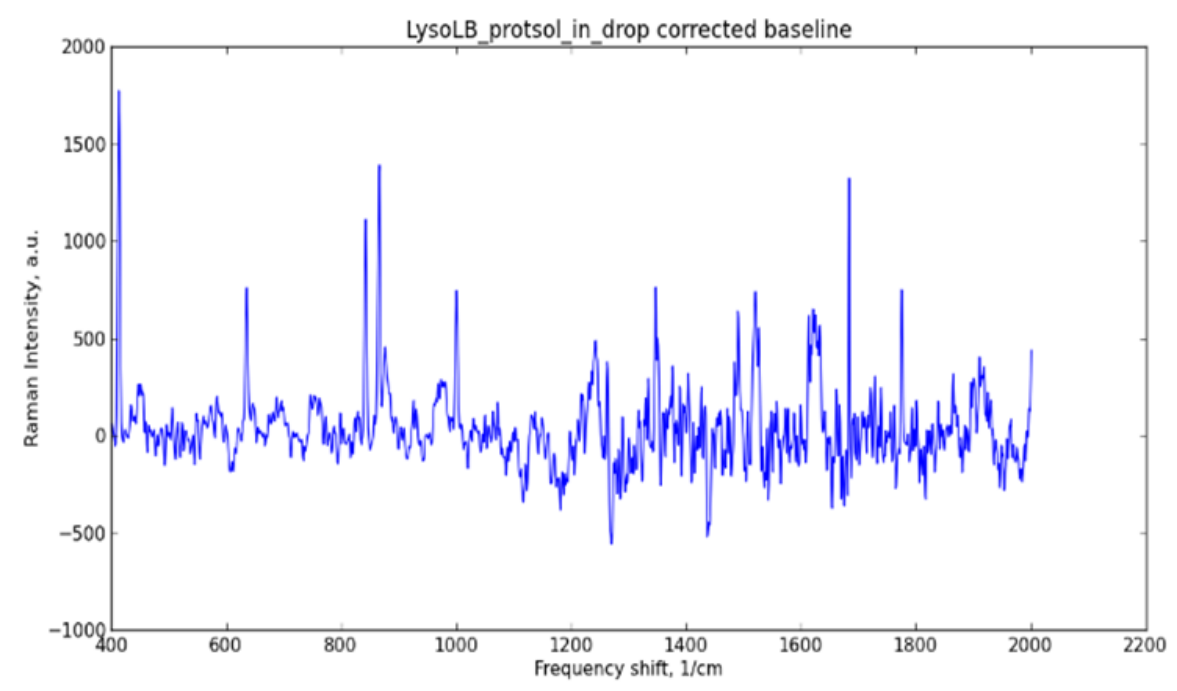

(a)

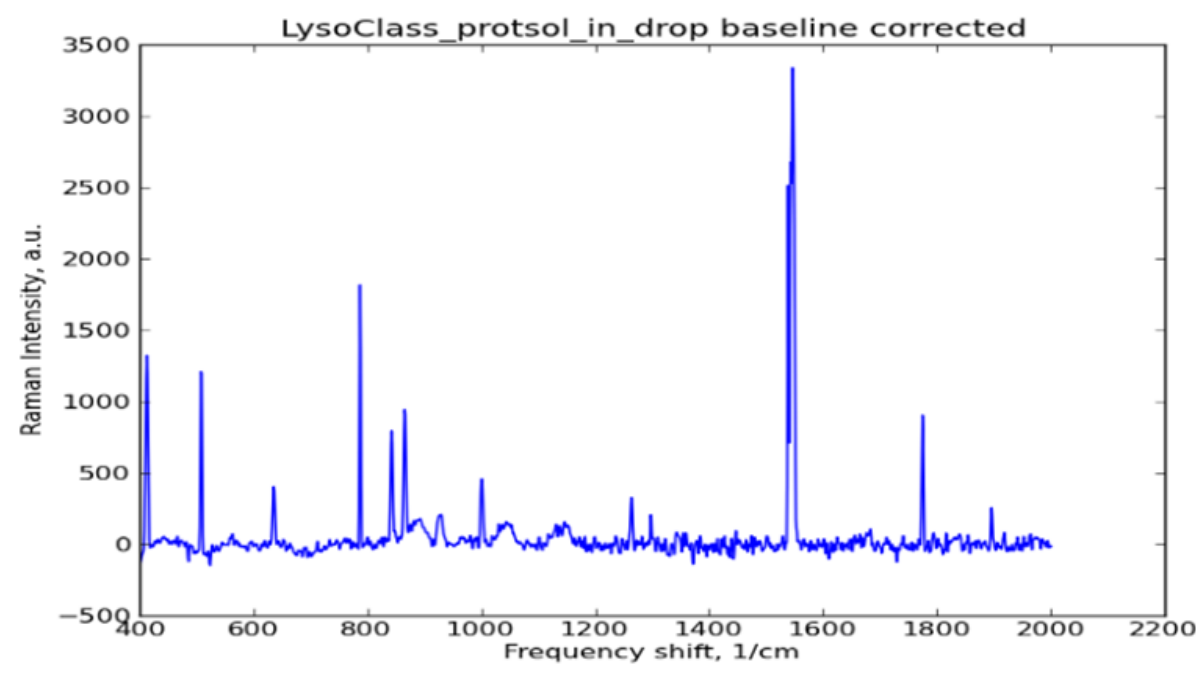

(b)

Figure 3: (A) LB Lysozyme baseline correction via software (B) Classical Lysozyme baseline correction via software. 
Citation: Nicolini C, Belmonte L, Maksimov G, Brazhe N, Pechkova E (2013) In situ Monitoring By Raman Spectroscopy of Lysozyme Conformation during "Nanotemplate" Induced Crystallization. J Microb Biochem Technol 6: 009-016. doi:10.4172/1948-5948.1000114

\begin{tabular}{|c|c|c|c|}
\hline Frequency shift, $1 / \mathrm{cm}$ & Bond vibration & Residue in lysozyme & Sensitivity \\
\hline 505 & $\begin{array}{l}\text { Disulfide bond } \\
\text { S-S }\end{array}$ & $\begin{array}{l}\text { There are four pairs of S-S bonds in lysozyme. } \\
\text { Two of them S6-S127 and S30-S115 are } \\
\text { close to the C-end }\end{array}$ & $\begin{array}{l}\text { Increase in peak intensity corresponds to the increase in the amount of S-S } \\
\text { bonds in lysozyme }\end{array}$ \\
\hline 634 & $\begin{array}{l}\text { C-S streching } \\
\text { mode in Cys } \\
\text { residues }\end{array}$ & Cys & Amount of Cys residues \\
\hline 760 & $\begin{array}{l}\text { Indole ring } \\
\text { breathing mode } \\
\text { of Trp }\end{array}$ & $\begin{array}{l}\text { Trp (there are } 6 \text { Trp in lysozyme, one of them } \\
\text { Trp123 locates closely to S6-S127, S30-S115 } \\
\text { in C-end) }\end{array}$ & Sensitive to the hydrophobic invironment. Characteristical peak of lysozyme \\
\hline $865-883$ & N1H site of Trp & Trp & $\begin{array}{l}\text { Frequency of the band depends on the strength of } \mathrm{H} \text {-bond between Trp and } \\
\text { other side-chain amino-acid residue. } 865-8711 / \mathrm{cm}-\text { in } \mathrm{H} \text { non-bond Trp; } 883 \\
\text { - in high H-bonding strength Trp residues }\end{array}$ \\
\hline 890,930 & $\begin{array}{l}\text { Backbone } \\
\text { C(alpha)-C, } \\
\text { C(alpha)-N }\end{array}$ & Peptide backbone & \\
\hline 1001 & $\begin{array}{l}\text { Ring breathing } \\
\text { of Phe }\end{array}$ & & \\
\hline $1010-1014$ & $\begin{array}{l}\text { Ring breathing } \\
\text { mode of Trp }\end{array}$ & $\operatorname{Trp}$ & \\
\hline
\end{tabular}

Table 2: Assignment of Raman peaks used in the comparative study.
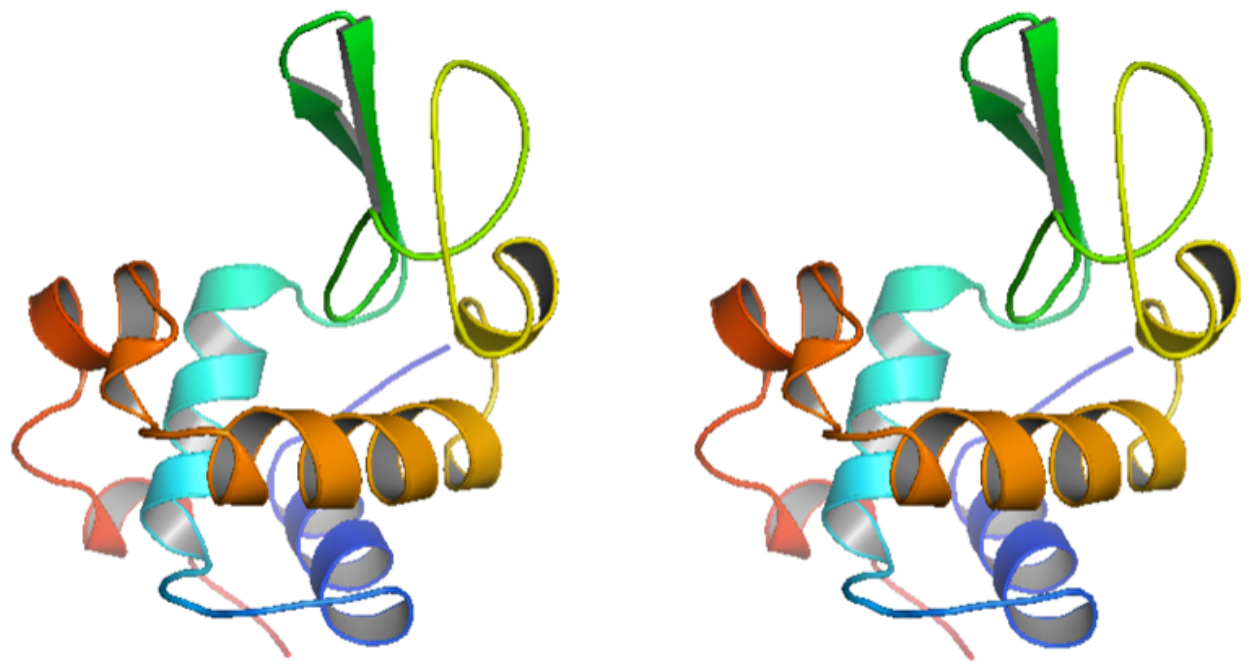

(a)
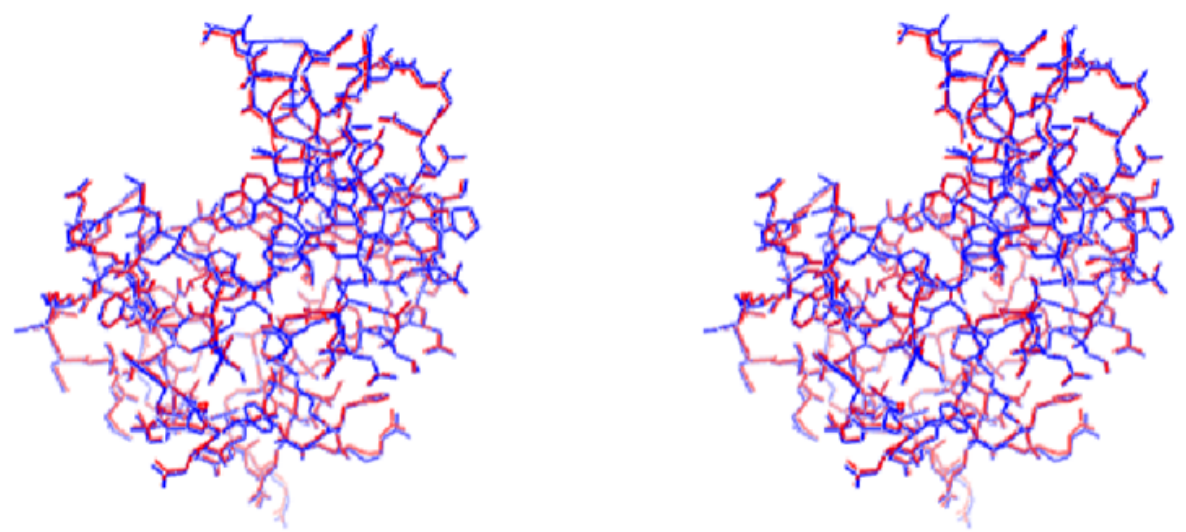

(b)

Figure 4: As described in results section of the manuscript (a) On the left Structure of the classical crystal grown Lysozyme and on the right structure of the LB crystal grown Lysozyme solved my X-ray protein crystallography. (b) Superposition of the two obtained structure of Lysozyme in blu the classical and in red the LB one. 
formation of S-S bonds resulting in the decrease of amount of SH- bonds in Cys residues. This is manifested in Raman Spectra as the increase in relative intensity of peak at $505 \mathrm{~cm}-1$ and the decrease in peak intensity at $634 \mathrm{~cm}^{-1}$ [35]. The relative inputs of Raman Spectra peaks at 760, 1001 and $1010 \mathrm{~cm}^{-1}$ into the spectrum (ratios of intensities I760/I865, I1010/I865 and I1010/I865) increase with time and corresponds to the increased manifestation of vibrations of indole ring, ring breathing of Trp and of ring breathing of Phe.

The difference in Raman Spectra with bonds vibrations in lysozyme for the lysozyme crystals depend on size by comparing lysozyme crystals of 50 and $150 \mu$, yielding changes in Raman spectra corresponding to formation of S-S bonds resulting in the significant decrease in the amount of SH- bonds in Cys residues (Figure 6). This is manifested in Raman spectrum of $150 \mu$ lysozyme crystals as a huge increase in relative intensity of peak at $505 \mathrm{~cm}-1$ and vanishing of peak at $634 \mathrm{~cm}^{-1}$. The relative inputs of peaks at 760,1001 and $1010 \mathrm{~cm}^{-1}$ into the spectrum of the larger lysozyme crystal (ratios of intensities I760/ I865, I1010/I865 and I1010/I865) are significantly higher (especially ratios I1010/I865 and I1010/I865) than the inputs of the same RS peaks of the smaller lysozyme crystal. This corresponds to the increased manifestation of vibrations of indole ring, ring breathing of Trp and of ring breathing of Phe.

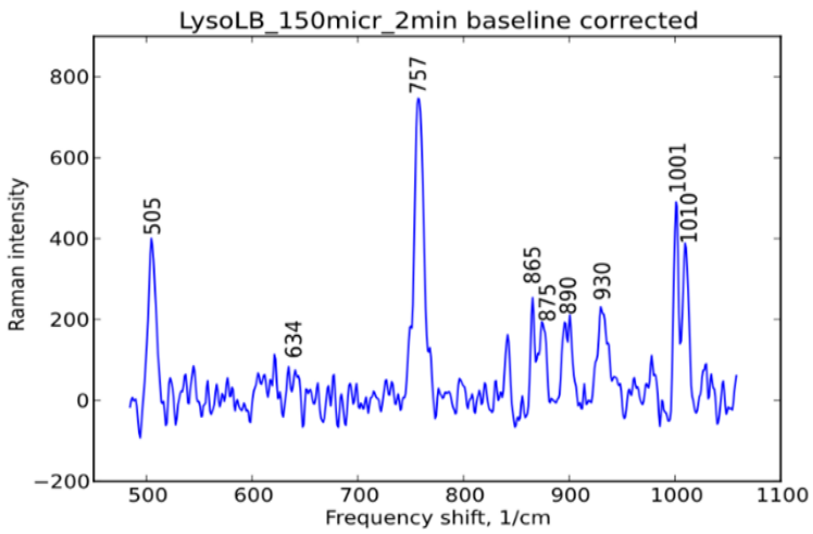

(a)

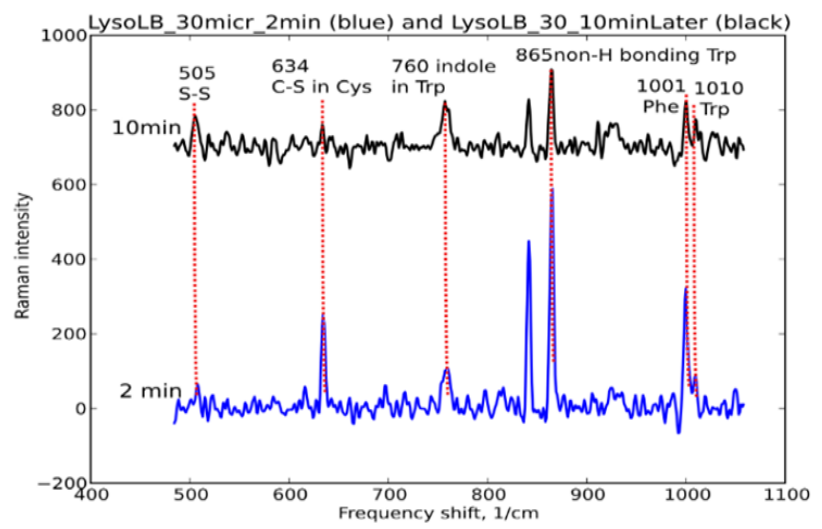

(b)

Figure 5: (A) Raman spectrum of Lysozyme LB, 150 micron. (B) Conformation of lysozyme in crystals LB of the same size changes with time.

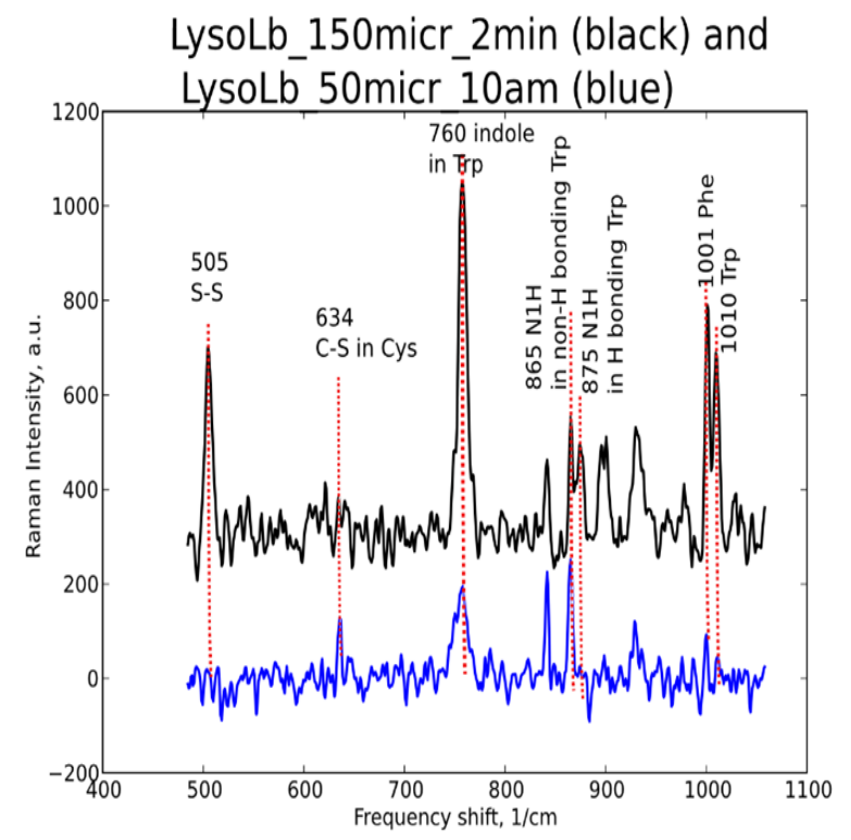

Figure 6: Conformation of lysozyme in LB crystals changes with the change in the crystal size.

We observed the appearance of Raman Spectra peak at $875 \mathrm{~cm}^{-1}$ in lysozyme crystal of 150 micron size that can be due to the formation of H-bond between Trp residues with other side-chain amino-acids. There is an increase in the relative intensities of peaks at 890 and 930 $\mathrm{cm}^{-1}$ in $150 \mu$-sized lysozyme crystal corresponding to the increased input of vibrations of C(alpha)-C and C(alpha)-N bonds. Such a change can be due to the conformational change in the backbone of lysozyme molecules in the $150 \mu$ crystal. The difference between RS of lysozyme in LB and classical crystals corresponding to the difference in their conformation and bond vibrations was found (Figure 7). Indeed, LB and classical crystals of the same $30 \mu$ size taken at the same time after nucleation differ drastically in their conformation, as can be monitored by their Raman Spectra differences displaying: higher amount of S-S bonds in LB crystal than in the classical and the decreased amount of SH-bonds in Cys residues. This is manifested in Raman spectrum of LB crystal $(30 \mu)$ as appearance of peak at $505 \mathrm{~cm}^{-1}$ and the decrease in intensity of peak at $6341 \mathrm{~cm}^{-1}$. In LB crystal there is the increased manifestation of vibrations of indole ring, ring breathing of Trp and of ring breathing of Phe. This can be seen as the significant increase in the relative inputs of peaks at 760, 1001 and $1010 \mathrm{~cm}^{-1}$ into the RS of the LB lysozyme crystal (ratios of intensities I760/I865, I1010/I865 and I1010/I865, and especially ratios I1010/I865 and I1010/I865) in the comparison to the classical crystal.

These RS changes between LB and classical crystals are very similar to the changes that are observed between large and small LB crystals and between LB crystals of the same size, but on the different points of time after nucleation.

We suppose that difference between LB and classical crystals and changes observed for larger lysozyme LB crystals and for LB crystals with different time after nucleation occur near the C-end of lysozyme, since this region is the most sensitive to any environmental changes [35]. 
Citation: Nicolini C, Belmonte L, Maksimov G, Brazhe N, Pechkova E (2013) In situ Monitoring By Raman Spectroscopy of Lysozyme Conformation during "Nanotemplate" Induced Crystallization. J Microb Biochem Technol 6: 009-016. doi:10.4172/1948-5948.1000114

We suggest in Figure 7 that LB crystal growing with time is accompanied by:

1. Formation of S-S bonds S6-S127/S30-S115 that brings Trp123 into new position and facilitates vibrations of its rings. It could also promote formation of $\mathrm{H}$-bond between Trp indole ring and the nearby amino acids;

2. Formation of S-S bonds S6-S127/S30-S115 that brings the whole C-end closer to Phe31 and Phe38 residues. This affects Phe rings vibrations;

3. Formation of S-S bonds in C-terminal that affects the conformation of the C-terminal and, possibly, the whole lysozyme. C-terminal is more rigid in LB crystals than in classic crystals and in larger LB crystals than in smaller one. This can produce more rigid and stable crystals.

We suggest that the main difference in lysozyme conformation in LB and classical crystals is caused by higher amount of S-S bonds in lysozyme of LB crystals, probably in C-end of protein, resulting in the higher stiffness of lysozyme molecules and LB crystal in a whole. Development of LB crystal in time and increase in its size is also accompanied by the formation of S-S bonds.

For what concern x-ray diffraction experiment LB lysozyme statistics are better in terms of quality parameters such Rfactor and Rfree of 0.175 and 0.241 respectively while for classical an Rfactor and Rfree of 0.195 and 0.259 were found for classical. As showed in Figure 4 minor differences were found in the two solved structures. Statistics are showed in Table 1 while images of the two structures are showed in Figure $4 \mathrm{~A}$ and $\mathrm{B}$.

\section{Conclusion}

Raman spectroscopy provided us a powerful technology to probe structural protein alteration during their crystallization by LB nanotemplate. Monitoring of water molecules was possible with this

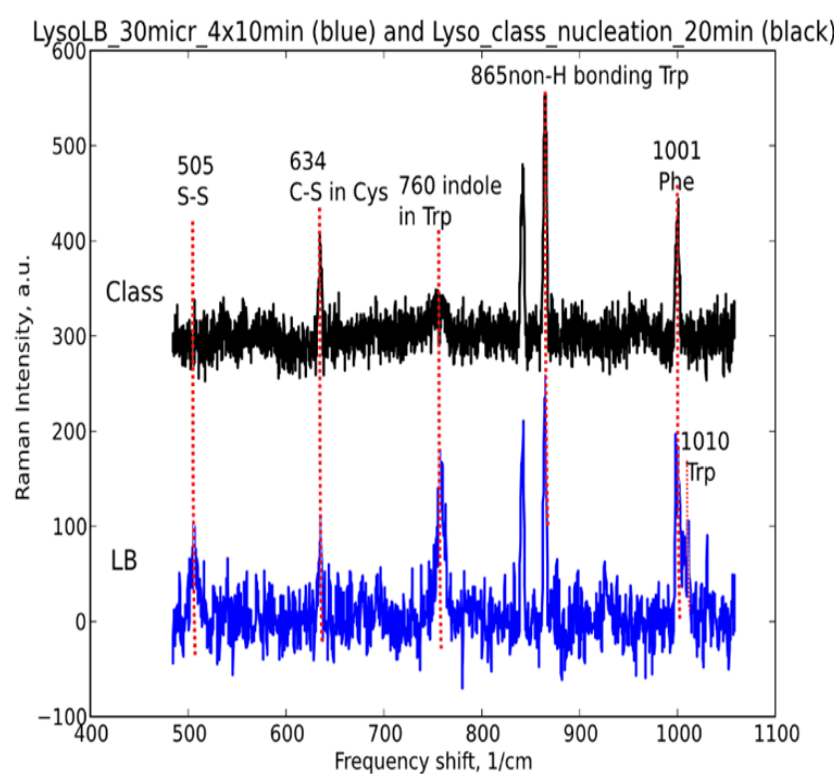

Figure 7: Conformation of lysozyme in LB crystal differs from conformation in classical crystal.

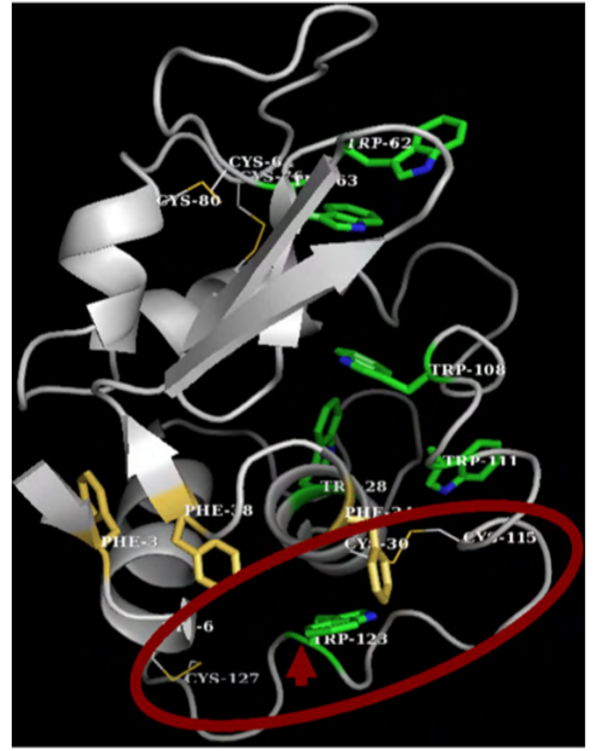

Figure 8: Difference in lysozyme conformation in LB and classical crystals is caused by higher amount of S-S bonds in lysozyme of LB crystals, probably in C-end of protein, Figure from Chandra et al. [34] a comparison with LB Lysozyme is performed see Pechkova et al. [22]

latter technique as was theorized, about water molecules redistribution, in previous work about LB protein nanotemplate $[17,18]$. In particular, in this manuscript we focused on Raman Spectroscopy of lysozyme crystals growth either with classical method or with LB nanotemplate method. We found two different organizations of the same protein and results (such as stiffness) are improved for the LB crystal grown. In the past we showed how the amount of the water molecules - and their arrangement - affects the crystallization process [18]. As showed in different papers, LB offer a 2D structure with which crystal protein can grown faster, easier, and, we suppose, in a much ordered way [36]. In a more ordered structure, therefore, it is assumed that water molecules tend to arrange themselves in a more orderly manner around the protein. From our perspective this is the reason of the quality differences between these two types of crystals and the higher radiation damage resistance improvement, due to a minor production of free radicals. These latter brought us to think that Raman spectrometry is optimal to monitor crystal growth in solvent, with and without thin film. Thanks to Raman spectrometry we are able to suggest that the main difference in lysozyme conformation in LB and classical crystals is caused by higher amount of S-S bonds in lysozyme of LB crystals, probably in C-end of protein, resulting in the higher stiffness of lysozyme molecules and LB crystal in a whole. Development of LB crystal in time and increase in its size is also accompanied by the formation of S-S bonds.

\section{Acknowledgement}

This project was supported by MIUR (Ministero dell'Istruzione, Università e Ricerca) to Fondazione Elba Nicolini with annual grants for "Funzionamento" and to Professor Claudio Nicolini at the University of Genova for FIRB Italnanoitalnet RBPR05JH2P 04. We are grateful to Carpentier Philippe for his assistance in collecting the Raman data at the Cryobench of ID23 at ESRF and to Alexey Brazhe for the help with Raman data analysis diffusion hanging drop.

\section{References}

1. Brazhe NA, Treiman M, Brazhe AR, Find NL, Maksimov GV, et al. (2012) Mapping of redox state of mitochondrial cytochromes in live cardiomyocytes using Raman microspectroscopy. Plos One 7: 1-8. 
Citation: Nicolini C, Belmonte L, Maksimov G, Brazhe N, Pechkova E (2013) In situ Monitoring By Raman Spectroscopy of Lysozyme Conformation during "Nanotemplate" Induced Crystallization. J Microb Biochem Technol 6: 009-016. doi:10.4172/1948-5948.1000114

2. Nicolini C, Pechkova E (2006) Structure and growth of ultrasmall protein microcrystals by synchrotron radiation: I. microGISAXS and microdiffraction of P450scc. J of Cellular Biochemistry 97: 544-552.

3. Pechkova E, Nicolini C (2006) Structure and growth of ultrasmall protein microcrystals by synchrotron radiation: II. microGISAX and microscopy of lysozyme. J of Cellular Biochemistry $97: 553-560$.

4. Cooper JB, Wise KL, Groves J, Welch WT (1995) Determination of Octane Numbers and Reid Vapor Pressure of Commercial Petroleum Fuels Using FTRaman Spectroscopy and Partial Least-Squares Regression Analysis. Anal Chem 67: 4096-4100.

5. Schwartz AM, Berglund KA (1999) The use of Raman spectroscopy for in situ monitoring of lysozyme concentration during crystallization in a hanging drop. $J$ of Crystal Growth 203: 599-603.

6. Schwartz AM, Berglund KA (2000) In situ monitoring and control of lysozyme concentration during crystallization in a hanging drop. J of Crystal Growth 210: 753-760.

7. Pechkova E, Tropiano G, Riekel C, Nicolini C (2004) Radiation stability of protein crystals grown by nanostructured templates: synchrotron microfocus analysis. Spectrochimica Acta B59 : 1687-1693.

8. Pechkova E, Tripathi S, Ravelli RBG, McSweeney S, Nicolini C (2009) Radiation Stability of Proteinase K Crystals Grown by LB Nanotemplate Method. J of Strucutarl Biology 168: 409-418.

9. Belmonte L, Pechkova E, Tripathi S, Scudieri D, Nicolini C (2012) LangmuirBlodgett Nanotemplate and Radiation Resistance in Protein Crystals: State of the Art. Critical Reviews in Eukaryotic Gene Expression 22: 219-232.

10. Gebhardt R, Pechkova E, Riekel C, Nicolini C (2010) In Situ HGISAXS: II. Thaumatin Crystal Growth Kinetic. Biophysical Journal 99: 1262-1267

11. Pechkova E, Gebhardt R, Riekel C, Nicolini C (2010) In Situ $\mu$ GISAXS: I. Experimental Setup for Submicron Study of Protein Nucleation and Growth Biophysical Journal 99: 1256-1261.

12. Pechkova E, Fontani D, Riekel C, Roth S, Nicolini $C$ (2005) $\mu$ Gisaxs and protein nanotemplate crystallizaion: methods and instrumentation. J of Synchrotron Radiation 12: 713-716

13. Pechkova E, Nicolini C (2011) In situ study of nanotemplate-induced growth of lysozyme microcrystals by submicrometer GISAXS. J of Synchrotron Radiation 18: $287-292$.

14. Nicolini C, Pechkova E (2010) An Overview of Nanotechnology-based Functional Proteomics for Cancer and Cell Cycle Progression. Anticance Research 30: 2073-2080.

15. Pechkova E, Nicolini C (2001) Accelerated protein crystal growth by protein thin filmtemplate. J of Crystal Growth 231: 599-602

16. Nicolini C (1997) Protein-Monolayer engineering: principles and application to biocatalysis. Trends in Biotechnology 5: 395-401.

17. Pechkova E,Sivozhelezov V, Nicolini C (2007) Protein thermal stability: The role of protein structure and aqueous environment. Arch Biochem Biophys 466: 40-48

18. Pechkova E, Sivozhelezov V, Belmonte $L$ and Nicolini $C$ (2012) Unique water distribution of Langmuir-Blodgett versus classical crystals. J of Structural Biology 180: 57-64
19. Pechkova E, Nicolini C (2010) Domain organization and properties of LB lysozyme crystals down to submicron size. Anticancer Res 30: 2745-2748.

20. Pechkova E, Vasile F, Spera R, Nicolini, C (2005) Protein nanocrystallography: growth mechanism and atomic structure of crystal induced by nanotemplates. $\mathrm{J}$ of Synchrotron Radiation 12: 772-778.

21. Pechkova E, Fiordoro S, Fontani D, Nicolini C (2005) Investigating crystal growth mechanisms with and without LB template: protein transfer from LB to crystal. Acta Crystallogr D Biol Crystallogr 61: 809-812.

22. Pechkova E, Sivozhelezov V, Tropiano G, Fiordoro S, Nicolini C (2005) Comparison of lysozyme structures derived from thin film-based and classical crystals. Acta Crystallogr D Biol Crystallogr 61: 803-808.

23. Carpentier P, Royant A, Ohana J, Bourgeois D (2007) Advances in spectroscopic methods for biological crystals. 2. Raman spectroscopy. J App Cryst 40: 1113-1122

24. Nicolini C, Spera R, Festa F, Belmonte L, Chong S, et al. (2013) Mass Spectrometry and Florescence Analysis of Snap-Nappa Arrays Expressed Using E. coli Cell Free Expression System. J of Mass Spectrometry. J of Nanomedicine \& Nanotechnology (In Press).

25. Belmonte L, Spera R, Nicolini C (2013) SpADS: An R Package for Mass Spectrometry Data Preprocessing before Data Mining. J of Computer Science \& Systems Biology 6: 298-304

26. Brazhe A, Leslie AGW, Powell HR (2007) Evolving methods for macromolecular. Crystallography 245

27. Collaborative Computational Project, Number 4 (1994) The CCP4 suite: programs for protein crystallography. Acta Crystallogr D Biol Crystallogr 50: 760-763.

28. Matthews BW (1968) Solvent content of protein crystals. J Mol Biol 33: 491-497

29. Vagin A, Teplyakov A (1997) MOLREP: An Automated Program for MolecularReplacement. J Appl Cryst 30: 1022-1025.

30. Murshudov GN, Vagin AA, Dodson EJ (1997) Refinement of macromolecularstructure by the maximum-likelihood method. Acta Crystallogr D Biol Crystallogr 53: 240-255.

31. Murshudov GN, Vagin AA, Lebedev A, Wilson KS, Dodson EJ (1999) Efficient anisotropic refinement of macromolecular structures using FFT. Acta Cryst $D$ 55: 247-255.

32. Emsley P, Cowtan K (2004) Coot: model-building tools for molecular graphics Acta Cryst D60 :2126-2132.

33. Schrodinger, LLC (2010). The PyMOL molecular graphics system. Version $1.3 \mathrm{r} 1$

34. Chandra G, Ghosh KS, Dasgupta S, Roy A (2010) Evidence of conformational changes in adsorbed lysozyme molecule on silver colloids. International $\mathrm{J}$ of Biological Macromolecules 47: 361-365

35. Pechkova E, Nicolini C (2004) Protein nanocrystallography: a new approach to structural proteomics. Trends in Biotechnol 22: 117-122.

36. Pechkova E, Sivozhelezov V, Tropiano G, Fiordoro S, Nicolini C (2005) Comparison of lysozyme structures derived from thin-film-based and classical crystals. Acta Crystallogr D Biol Crystallogr 61: 803-808. 